\title{
THE DYNAMICS OF LANGUAGE AND CULTURE AMONGST ENGLISH SPEAKING CLINICAL PSYCHOLOGISTS IN KWAZULU-NATAL
}

BY: DR CONSTANCE NTOMBIFUTHI MKHIZE UNIVERSITY OF ZULULAND S.A.

email:cnmkhize@webmail.co.za

\section{Introduction}

$>$ There is a general increase in crosscultural counselling and psychotherapy where the client communicates in African languages while the therapist is English speaking.

$>$ Bearing in mind that psychology in general, is based on the western principles and ideologies.

$>$ South Africa has so many different ethnic groups and races that it makes it even more important to recognize and accept diversity

$>$ Clinical psychology services are largely dominated by English speaking psychologist.

$>$ There is a serious lack of black psychologists in mental health. $>$ Interracial psychotherapy challenges are likely to cause ambivalent feelings, attitudes and uncertainties in a therapeutic relationship. $>$ Maintenance of multicultural counselling competence may be one of the most important ethical issues the counselling profession faces in today's diverse society (Harper \& McFadden, 2003).

\section{Motivation of the study}

$>$ Health care professionals have convinced themselves that language is not a problem in the way of appropriate care (Strous \& Eagle, 2004)

$>$ Lack of psychological services and the dynamics of language and culture in interracial psychotherapy, particularly in rural areas, lead to psychological services being perceived as irrelevant and inappropriate.

\section{Aim of the study}

The aim of the study was to investigate: $>$ How psychologists from different cultural and language background make sense of language and cultural diversity in their therapeutic relationship

$>$ The continuing challenges facing English speaking psychologists working interracially and how it affects the therapeutic.

\section{Methodology}

$>$ A discourse analytic approach was employed to understand the complicated language phenomenon in sharing sensitive and confidential material.

$>$ A convenient sample of five psychologists was drawn from general and psychiatric hospitals as well as those working in private practice.

$>$ The target population for this study included White and Indian psychologists. $>$ Eight participants were selected for this study.

$>$ The transcripts of three participants were eventually abandoned due to poor quality of the taped interview.

$>$ All the participants had experience in working with diverse cultures and people who are speaking isizulu.

\section{Research Findings and recommendations}

There were interesting dynamics that came up from the data collected as follows:

$>$ Interpreters as culture mediators

$>$ Interpreters establish trust in a therapeutic relationship

$>$ Communicating through the interpreter $>$ Language dynamics

$>$ Lack of self confidence

$>$ Confusion with role ambiguity

$>$ Accommodating other people's culture $>$ Lack of spontaneity

$>$ Focus on study that will investigate the impact of interpreters in the therapy process.

$>$ Greater investment in future empirical research that would determine if psychology is suitable for African patients.

$>$ Investigate the ethical considerations to the use of interpreters.

$>$ Need for training interpreters in the field of psychology

$>$ Need for ongoing in-depth professional development for psychologists on multicultural psychotherapy issues

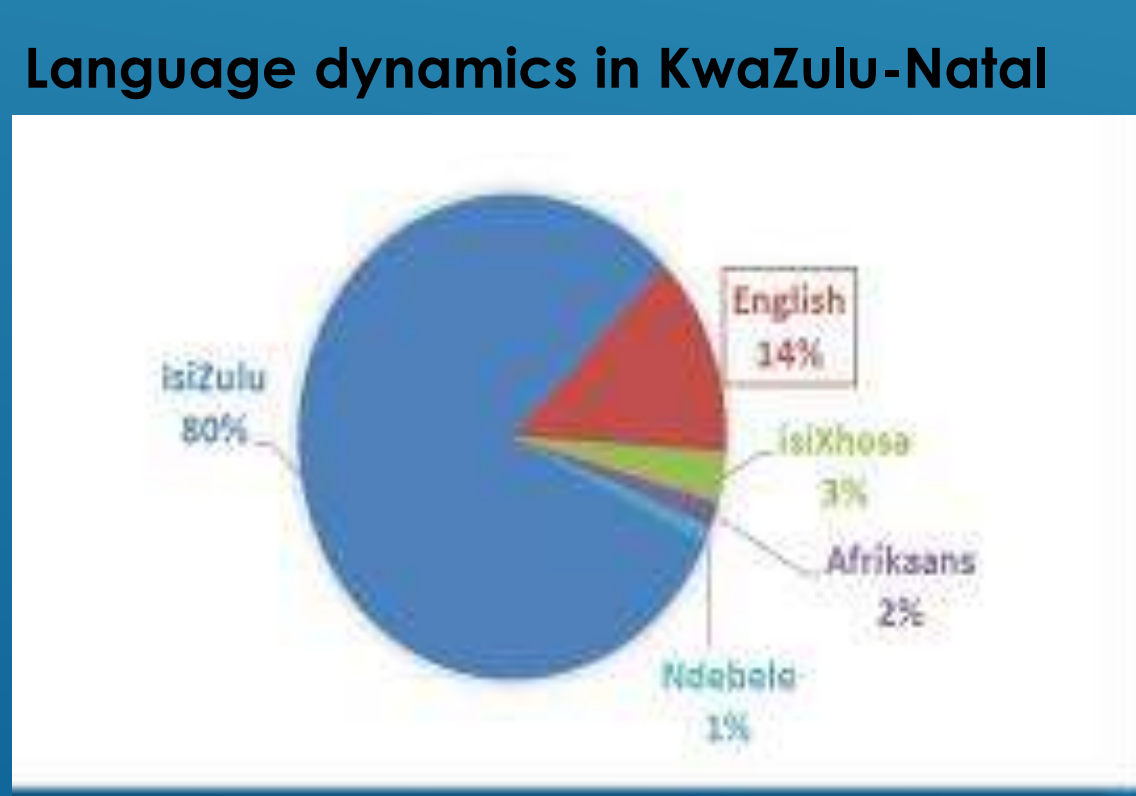

\section{Conclusion}

$>$ From the results it was identified that patients are disadvantaged of the psychological services because of the language they do and do not speak.

$>$ English speaking psychologists experience serious challenges when they have to conduct psychotherapy and other related activities with non-English speaking patients/clients.

$>$ The issue of working with interpreters continues to be faced with many uncertainties. While the interpretation process is by no means ideal for carrying out psychotherapeutic work, however, it can go a long way in creating access to psychological services.

$>$ Psychotherapy can be implemen successfully through using interpreters, such time that the system is produce psychologists that are proficient in different indigel spoken in South Africa.
re a

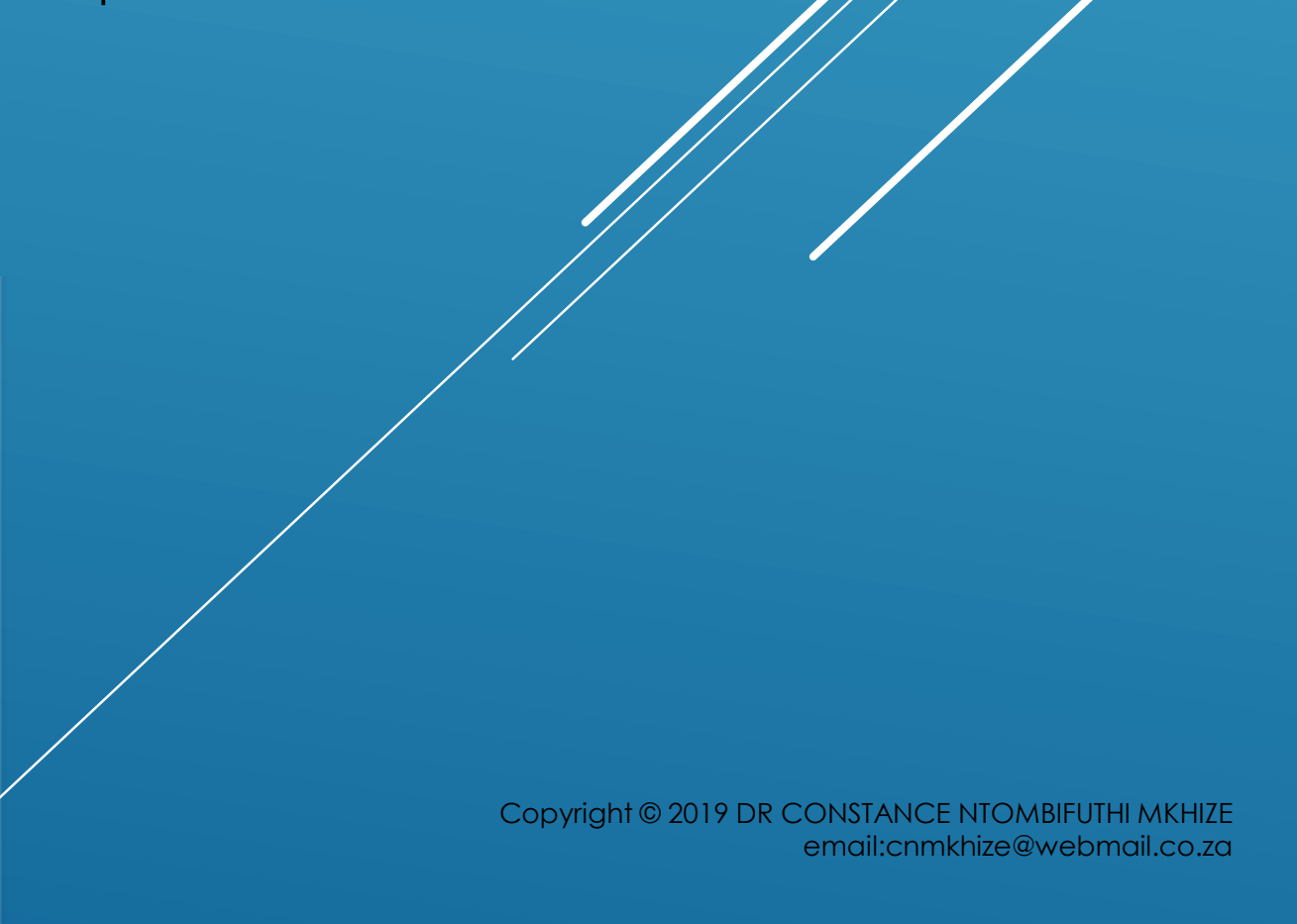

